\title{
Recent activities of titanium research and development in Japan
}

\author{
Takayuki Narushima ${ }^{1, *}$ and Yasuaki Sugizaki ${ }^{2,3}$ \\ ${ }^{1}$ Professor, Department of Materials Processing, Tohoku University \\ ${ }^{2}$ Chairman, The Japan Titanium Society \\ ${ }^{3}$ President, Member of the Board, Osaka Titanium technologies Co., Ltd. \\ *narut@material.tohoku.ac.jp
}

\section{$\underline{\text { Abstract }}$}

The research and development of Ti and its alloys as well as progress in Japan's Ti industries and markets are described. Academic and industrial advances and activities over the past four years, since the $13^{\text {th }}$ World Conference on Titanium held in San Diego, USA, are overviewed.

\section{Introduction}

This paper provides an overview of the progress related to Ti in Japan, four years after the $13^{\text {th }}$ World Conference on Titanium. First, the production of Ti sponge and mill products, as summarized by the Japan Titanium Society (JTS), is reviewed. Next, academic activities including national projects are discussed. Finally, related progress across various industries is described. Thereafter, the chemical composition of the alloys is denoted by mass percent and the notation mass percent is omitted unless otherwise stated.

\section{Titanium production in Japan [1]}

Ti sponge shipments have been increasing since 2013. Shipments reached 50,468 $\mathrm{t}$ in 2017, which was 8,000 $\mathrm{t}$ more than those in 2016, and the third highest quantity recorded in Japan (Fig. 1). The increase in 2107 was mainly due to an increase in the exports from 18,230 $\mathrm{t}$ in 2016 to $24,110 \mathrm{t}$ in 2017. Domestic shipments also increased by $2,258 \mathrm{t}$ in 2017 . Ti mill product numbers have been increasing for five consecutive years from 2013 to 2018; numbers reached 18,922 t in 2018 andare approaching the highest quantity ever (Fig. 2). Plate-type heat exchangers (PHE), power generation, electrolytic equipment, and aircraft account for $74 \%$ of the total demand for mill products. Demand for automotive, distributors,consumer goods, and medical are also significant (Fig. 3). New demand development has contributed to an increase in shipments. Figures 4 and 5 represent Japan's share in the global production of Ti sponge and mill products in 2017. Japan was the second largest producer of Ti sponge in the world in 2017.

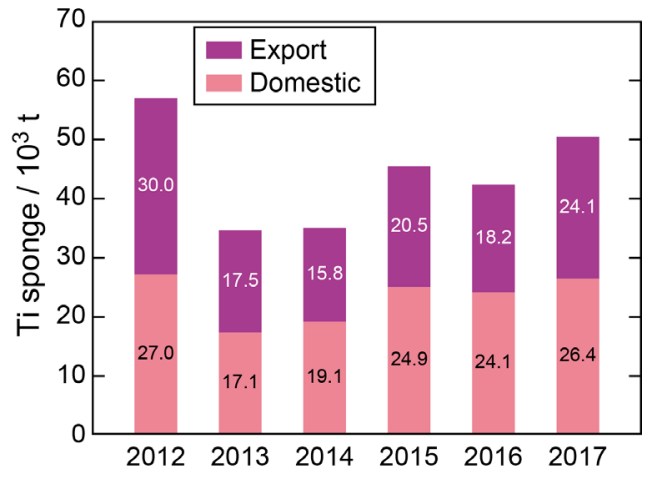

Figure 1 Ti sponge shipments in Japan from 2012 to 2017 [1].

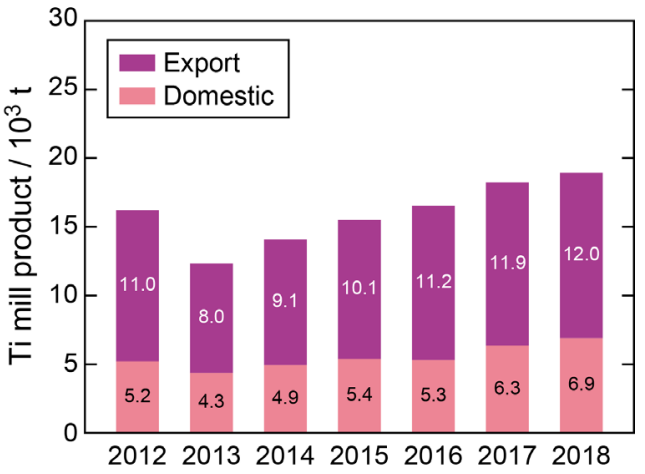

Figure 2 Ti mill product shipments in Japan from 2012 to 2018 [1].

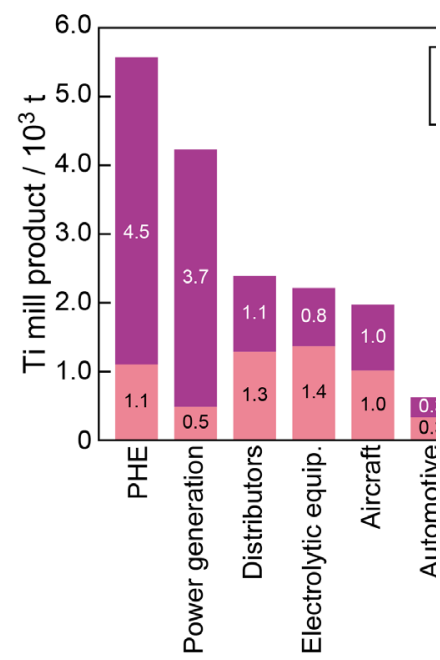

Figure 3 Application-wise Ti mill product shipm 


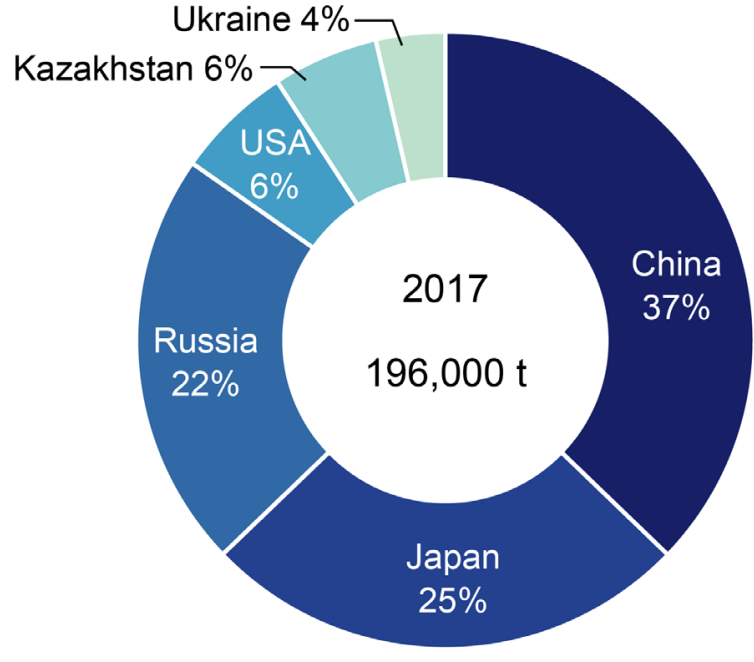

Figure 4 Japan's share in global Ti sponge production in 2017 [1].

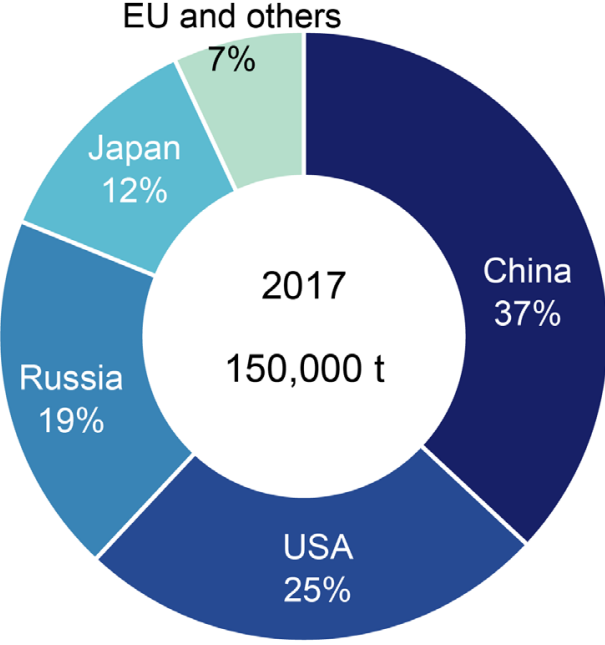

Figure 5 Japan's share in global Ti mill products in 2017 [1].

\section{National projects on titanium}

The cross-ministerial Strategic Innovation Promotion Program, SIP, is a national project promoted by the Council for Science, Technology and Innovation (CSTI) of the Government of Japan to realize scientific and technological innovation. The first SIP was executed from October, 2014 to March, 2019. It targeted eleven scientific and technological research topics, including "Structural Materials for Innovation" [2], which comprised four research domains, namely, Polymers and CFRP (carbon fiber reinforced plastic), Heat Resistant Alloys and Intermetallic Compounds, Ceramic Matrix Composites, and Materials Integration System. Under the "Heat Resistant Alloys and Intermetallic Compounds" domain, processing technologies such as casting, forging, laser metal deposition, metal injection molding (MIM), and 3D additive manufacturing (AM) for Ti alloys, Ni-based superalloys, and TiAl for aerospace applications were developed to improve material performance [3]. Subsequently, research on "Development of innovative forging process technology and material/process database with the large-scale and precise forging simulator" was initiated. Four industries, nine universities, and one national research institute cooperated for this research, which lasted 4.5 years, under a total budget of 2,470,350,000 JPY (nearly 22,000,000 USD).

Mechanical properties of $\mathrm{Ti}$ alloys for aero engines are strongly dependent on thermo-mechanical processing. Precise processing simulations and microstructure prediction are critical to obtain desirable mechanical properties. Therefore, a $1500 \mathrm{t}$ forging press was installed in NIMS (National Institute for Materials Science), Japan, to gather data pertaining to plastic deformation, microstructure, and mechanical properties under various processing conditions. The forging press is controlled by hydraulic pressure; it consists of a furnace for prior heat treatment of specimens, a die heater, an annealing furnace, and a cooling system. It can control the temperature of the materials precisely using the die heater and the cooling system. Specifications of the forging press are listed in Table 1 .

A processing map using the small forging press was established to verify initial microstructures and understand appropriate processing conditions [4]. Then, microstructures of as-forged Ti alloys under different forging conditions were observed. Constitutive equations that modeled the microstructural evolution of the specimens were established [5] and modified to predict the microstructure obtained using the $1500 \mathrm{t}$ forging press. Next, the forged specimens were solution treated and aged (STAed), their microstructure evolution was investigated, and a prediction model for STA was established [6]. The tensile strength and fatigue life of the specimens forged using the $1500 \mathrm{t}$ press and STAed were tested to understand the microstructural factors that control the mechanical properties, and a prediction model for tensile strength was established [7,8]. To apply the prediction model to the $1500 \mathrm{t}$ forging press, coefficients of friction and thermal transfer were determined by comparing experiments conducted using the hot forging emulating system and Finite Element Method (FEM)[9]. Established prediction models of microstructure and tensile strength of as-forged and STAed specimens were combined as subroutines in FEM software, which predicted microstructure and tensile strength on the basis of the forging conditions.

The prediction model constructed using the $1500 \mathrm{t}$ forging press was applied to a 50,000 $\mathrm{t}$ forging press for Ti alloys [10,11]. Large-scale forging was successfully accomplished, as shown in Fig. 6 . The expected load-stroke curve was fitted well with the experimentally obtained curve (Fig. 6 (c)). The tensile strength at different positions of the Ti alloy specimens, forged by the $50,000 \mathrm{t}$ forging press and STAed, was investigated and compared with the predicted strength. As shown in Fig. 7, the measured strength is fitted well with the predicted value. 


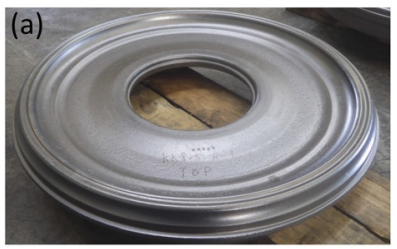

(b)

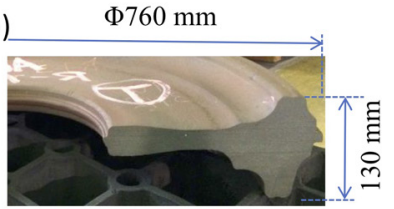

(c)

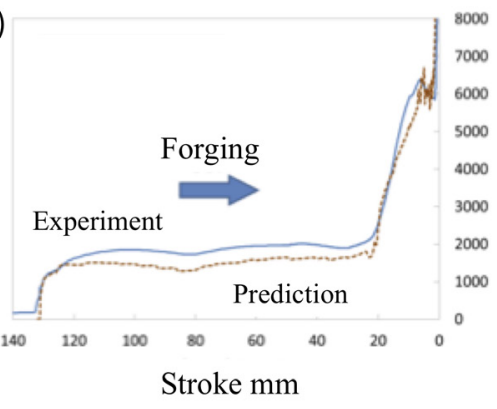

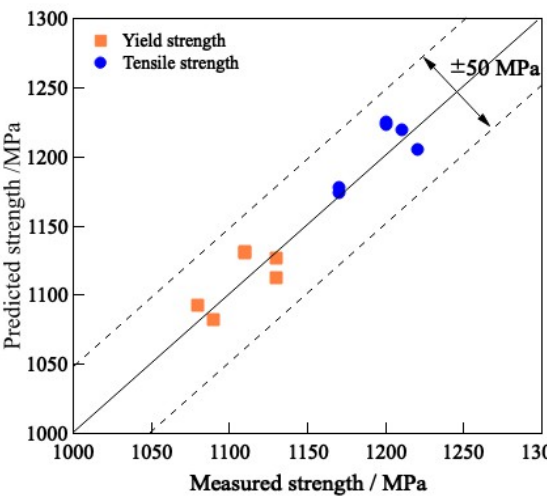

Figure 7 Comparison of predicted and measured strength of Ti alloy product $50,000 \mathrm{t}$ forging press and STAed. (Courtesy of Dr. Yamabe-Mitar

\section{Reduction and refining}

Studies on the reduction of Ti oxide and solid and liquid Ti refining are actively conducted in Japan. A new metallurgical process for metallic Ti production using Ti sulfide from ilmenite (TiFeO ${ }_{3}$ ) was proposed (Fig. 8) [12,13]. In this process: 1) the ilmenite ore is converted to $\mathrm{TiO}_{2}$ upon exposure to gaseous $\mathrm{CS}_{2}$ at $1173 \mathrm{~K}$ and the FeS by-product is wet-chemically removed, 2) the residual oxide is exposed again to gaseous $\mathrm{CS}_{2}$ to form $\mathrm{TiS}_{2}$ [14], and 3) $\mathrm{TiS}_{2}$ is electrochemically reduced to metallic Ti using molten $\mathrm{CaCl}_{2}$-CaS as an application of the OS process (Fig. 9), where the $\mathrm{S}_{2}$ by-product (gas) can be used to synthesize $\mathrm{CS}_{2}$. This process utilizes the low solubility of sulfur in Ti that coexists with Ti sulfides. Although Ti sulfides do not exist in nature, $\mathrm{TiS}_{2}$ can be obtained when TiFeO $\mathrm{O}_{3}$ reacts with gaseous $\mathrm{CS}_{2}$. The $\mathrm{OS}$ process was applied to $\mathrm{TiS}_{2}$ under low oxygen concentration and Ti powders with unique flat-plate type shape, with around 1 mass $\%$ oxygen concentration; the sulfur concentration was successfully reduced to a low level of 21 mass ppm. In addition, carbon contamination in the Ti powders was avoided due to absence of $\mathrm{CO}_{2}$ re-dissolution in the $\mathrm{OS}$ process.
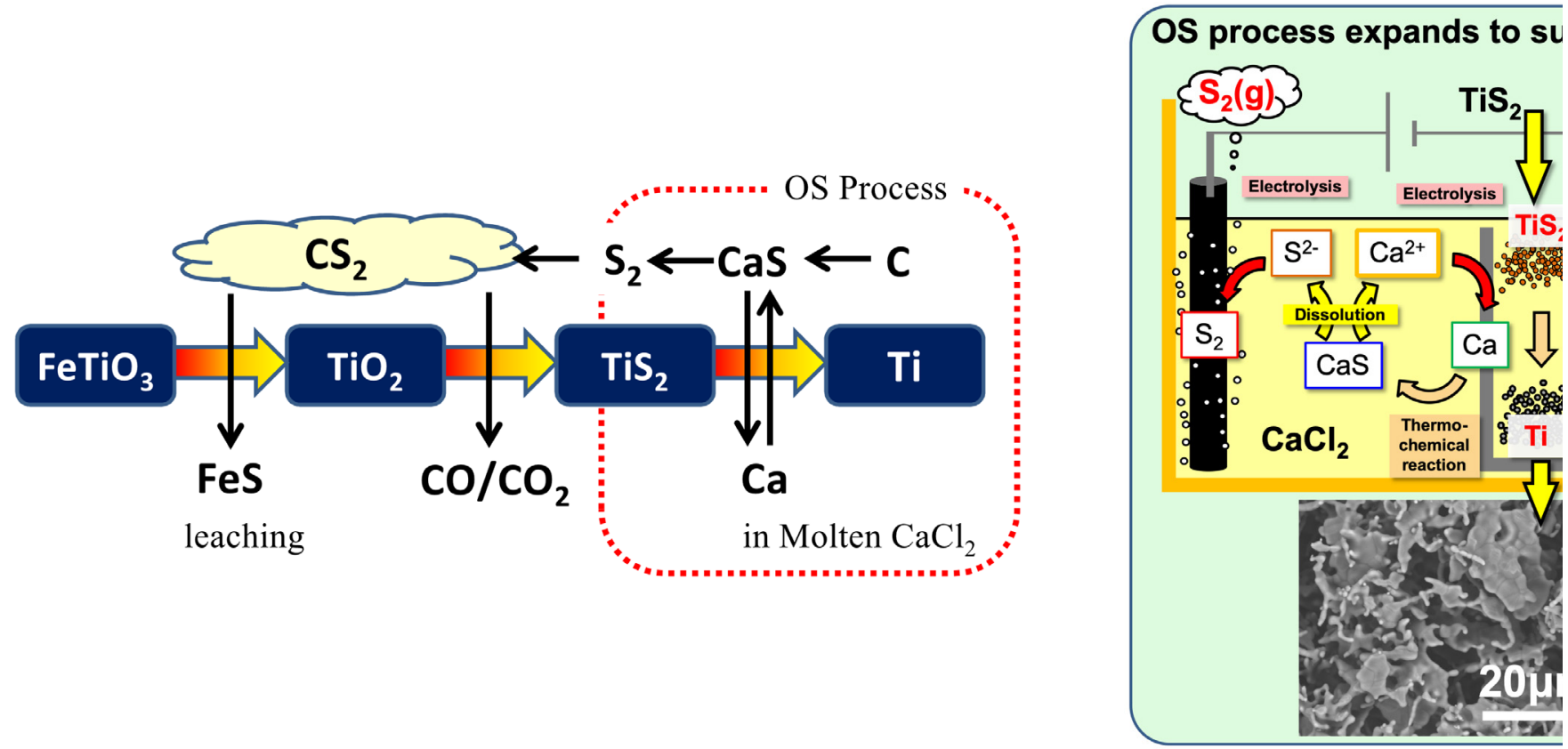

Figure 9 Electrochemical reduction of $\mathrm{TiS}_{2}$ to metallic Ti using molten $\mathrm{C}$ of $\mathrm{OS}$ process [14].

Low cost raw materials, such as off-grade Ti sponge and low grade Ti scraps are not easy to use in the melting process due to difficulty in removing impurities. Oxygen is the main impurity in low cost raw materials; thus, deoxidation of Ti melts can enable use of low cost raw materials and reduce the cost of Ti parts [15]. Hence, new deoxidation processes for solid and liquid Ti were introduced. A new two-step plasma arc melting process for oxygen removal from Ti melts, comprising $\mathrm{Ar}_{-} \mathrm{H}_{2}$ plasma arc melting (first step) and subsequent Ar plasma arc melting (second step) was proposed (Fig. 10) and change in the oxygen content of Ti melts was reported [16]. The deoxidation reaction of Ti melts occurs in the second step and is expressed by Eq. (1). 
Hydrogen introduced in the Ti melts in the first step functions as a deoxidizer in the deoxidation reaction of the second step. The introduced hydrogen can remove up to eight times its mass of oxygen (Eq. (1)) due to the difference in their atomic weight (1.01 and 16, respectively). Atomic hydrogen, which increases the hydrogen content in metallic melts compared to diatomic hydrogen ( $\left.\mathrm{H}_{2}\right)$, is dominant at common operating temperatures of most plasma furnaces and reactors [17]. Figure 11 depicts the oxygen content after the two-step plasma arc melting. The oxygen content in the surface region of the Ti melt decreased from the initial value of $1.5-1.6$ mass $\%$ to $\sim 0.7$ mass $\%$ [16].

Two-step plasma arc melting process using hydrogen

First step: Under $\mathrm{Ar}-\mathrm{H}_{2}$ flowing Hydrogen: Introduced into Ti melt
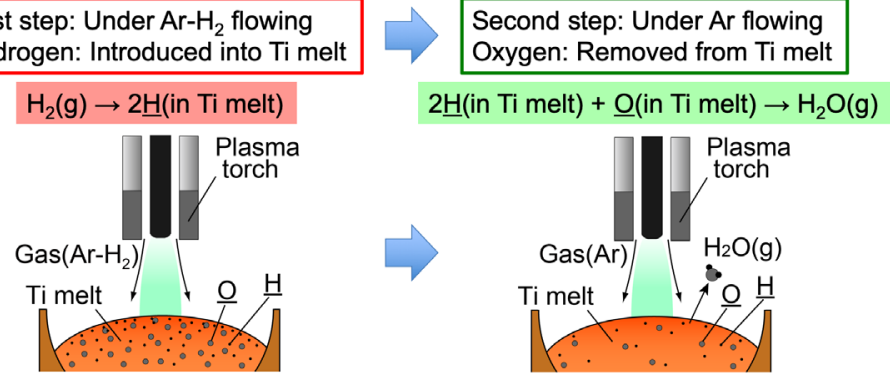

Figure 10 Schematic illustration and reactions of the two-step plasma arc melting [16].
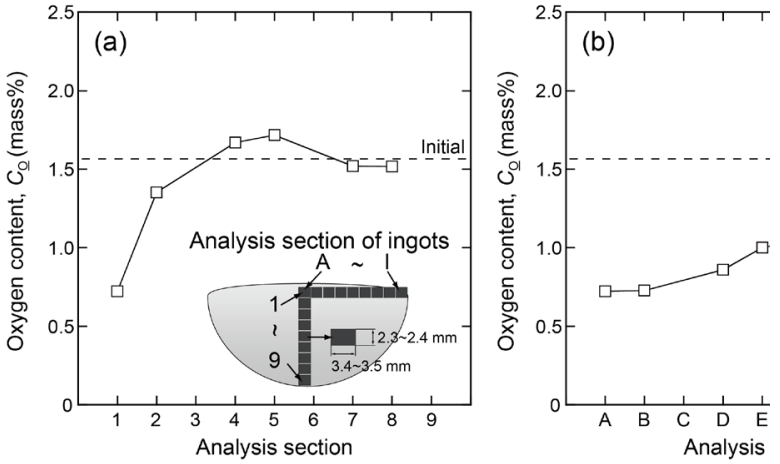

Figure 11 Oxygen content of Ti ingots after four cycles of melting under $\mathrm{Ar}-30 \% \mathrm{H}_{2}$ gas flow for 91 flow for $900 \mathrm{~s}$ in the (a) depth and (b) horizontal directions [16].

Further, Ti deoxidation with Al addition during melting was developed. As shown in Fig. 12 [18], oxygen content in Ti melts decreased with $\mathrm{Al}$ addition, independent of the type of melting process used, such as plasma arc melting (PAM) or cold crucible induction melting (CCIM). Oxygen was removed as $\mathrm{Al}_{2} \mathrm{O}_{3}$ in the Ti melts [18].

With respect to solid Ti deoxidation, thermodynamic considerations suggest that extra-low oxygen Ti, with 100 mass ppm or less oxygen, could be obtained using molten salt equilibration with rare earth metals ( $\mathrm{Y}$ or light rare earth metals ( $\mathrm{La}, \mathrm{Ce}, \mathrm{Pr}$, or $\mathrm{Nd}$ ) ) [19]. A new deoxidation technique for solid Ti was proposed by adding yttrium chloride $\left(\mathrm{YCl}_{3}\right)$ to magnesium chloride $\left(\mathrm{MgCl}_{2}\right)$ flux, which effectively decreased and maintained $\mathrm{MgO}$ activity at a low level through the formation of yttrium oxychloride (YOCl). Thermodynamic assessment and experiments confirmed that the deoxidation of solid $\mathrm{Ti}$ reduced the oxygen level below 1000 mass ppm (Fig. 13) [20], through the reaction, $\underline{\mathrm{O}}$ (in Ti(s)) $+\mathrm{Mg}+\mathrm{YCl}_{3} \rightarrow \mathrm{MgCl}_{2}+\mathrm{YOCl}$, at $1300 \mathrm{~K}$ after a reaction time of $173 \mathrm{ks}$. This new deoxidation technique using rare earth containing $\mathrm{MgCl}_{2}$ flux can be applied to recycle Ti scraps in the future.

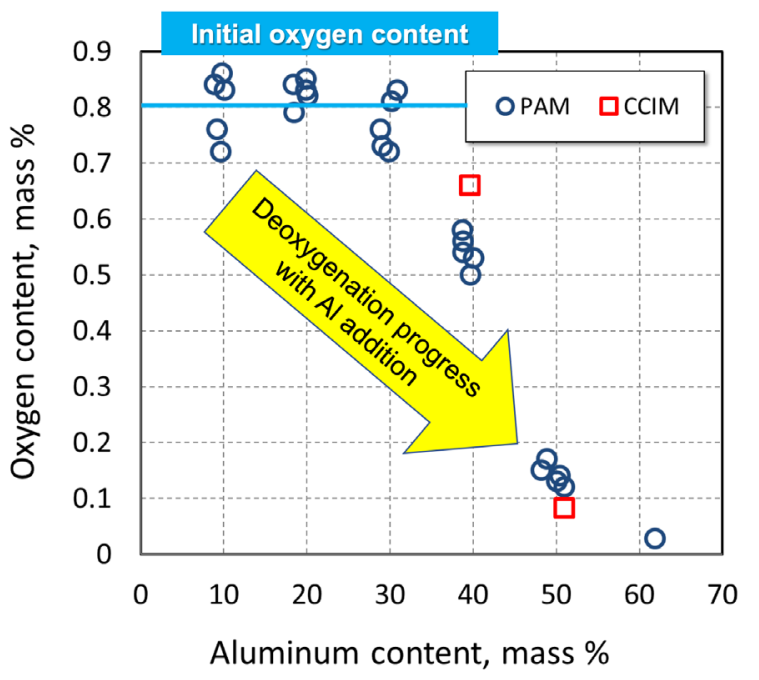

Figure 12 Oxygen content in Ti-Al melts after plasma arc melting (PAM) and cold crucible induction (CCIM) (Courtesy of Kobe Steel Ltd.).

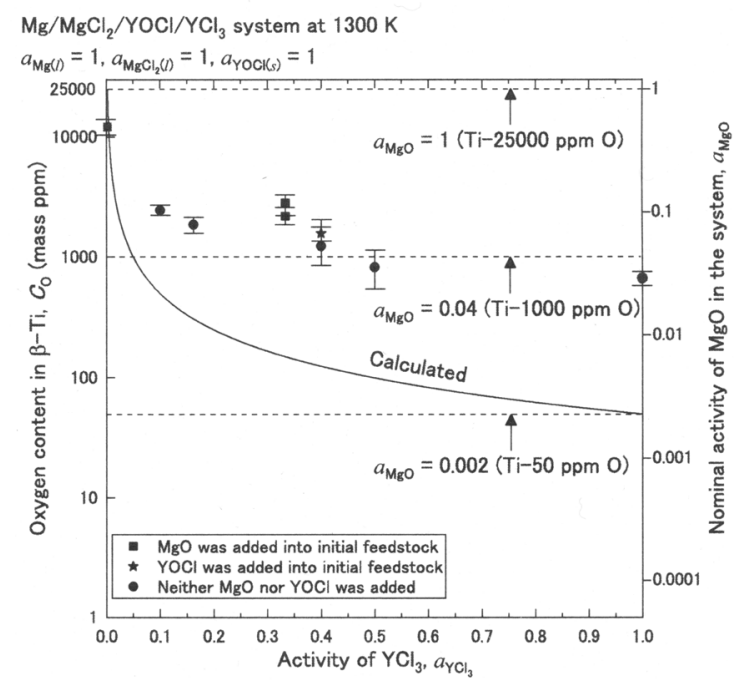

Figure 13 Experimentally determined oxygen content in solid $\mathrm{Ti}$ as a function of activity of $\mathrm{YCl}_{3}$ in $\mathrm{Mg} / \mathrm{MgO} / \mathrm{YOCl} / \mathrm{YCl}_{3}$ system at $1300 \mathrm{~K}$ [20].

\section{Alloy development}


Substantial quantities of forged and machined Ti alloys are used in aerospace components. A new Ti alloy with good forgeability and machinability is being developed to decrease the cost of forged and machined parts [21]. The new alloy is referred to as Ti-531CN and has the composition: Ti-4.5Al-2.5Cr-1.2Fe-0.12C-0.3Cu-0.3Ni. It has mechanical properties equivalent to Ti-6 Al-4V (Ti-64) alloy. Features of the new alloy include higher deformability and lower flow stress, and it can extend the life time of machining tools (Fig. 14) [21].

A cold formable $\beta$ type Ti alloy with the composition of Ti-20Nb-5Cr-4Zr (TNCZ) was developed for biomedical applications. It exhibits low Young's modulus, less than 70 GPa, and consists of non-toxic elements. The TNCZ alloy has relatively a low melting point as it is Ta-free, suppresses $\mathrm{Nb}$ content, and offers good formability of over $90 \%$ cold wire drawing (Fig. 15 ), resulting in excellent manufacturability.
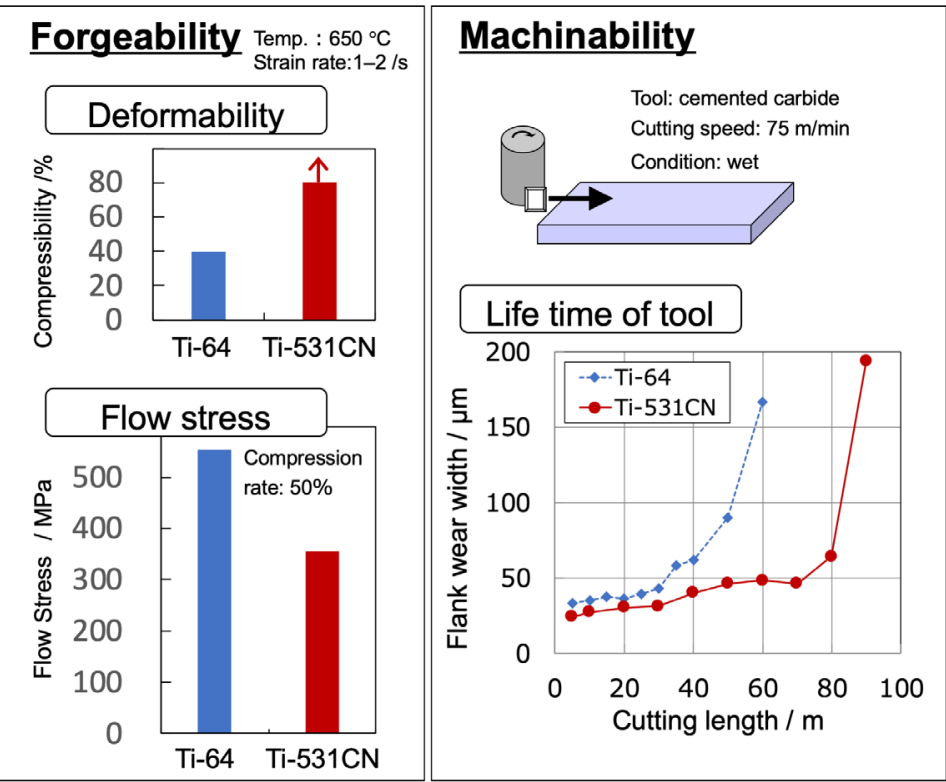

Figure 14 Workability of Ti-4.5Al-2.5Cr-1.2Fe-0.12C-0.3Cu-0.3Ni (Ti-531CN) alloy (Courtesy of Kobe Steel Ltd.).

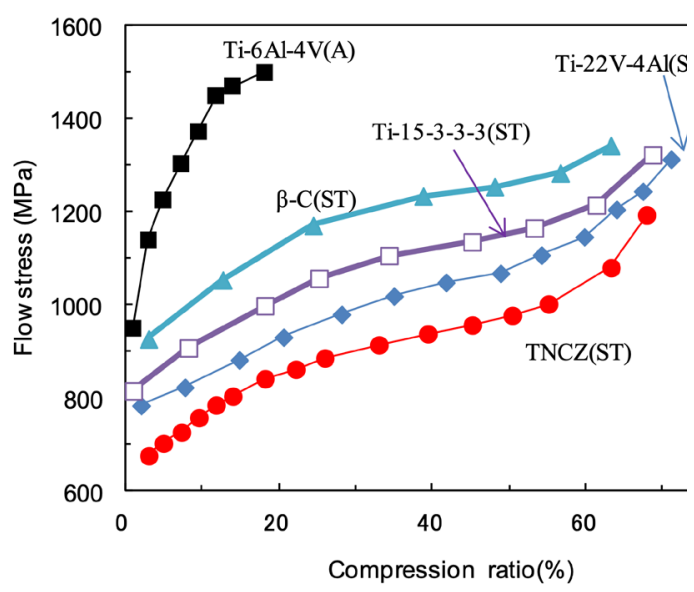

Figure 15 Cold workability of Ti-20Nb-5Cr-4Zr (TNCZ) alloy (Courtesy of Daido Stee

The microstructure and mechanical properties of the new Ti alloys have been assessed to improve heat resistance properties. Nb was selected as an alloying element in the new alloys to improve oxidation resistance. However, $\mathrm{Sn}$ was eliminated as it deteriorates the oxidation resistance. Moreover, $\mathrm{Zr}$ improved the oxidation resistance and simultaneous addition of $\mathrm{Nb}$ and $\mathrm{Zr}$ improved the adhesion of the oxide layer. Thus, Ti-(10-15)Al-(0,2) Nb-(1,2)Zr alloys (at\%) were designed [22] and their mechanical properties, particularly the effect of $\alpha_{2}-\mathrm{Ti}_{3} \mathrm{Al}$ precipitates on the strength, were examined [23]. The strength significantly improved in the moderate temperature range (573-723 K) following $\alpha_{2}-\mathrm{Ti}_{3} \mathrm{Al}$ precipitation. Creep properties were also investigated and the deformation mechanism was analyzed using an Arrhenius-type equation for Ti-Al-Nb-Zr-Si alloys [24]. Based on the stress exponent and activation energy, the deformation mechanism of the creep deformation was identified as high temperature powerlaw creep controlled through lattice diffusion.

High-entropy alloys (HEAs) must be single-phase solid solutions and contain five or more principal elements, with individual concentrations 5-35 at\% [25]. An equiatomic TiNbTaZrMo HEA containing biocompatible elements was developed as a metallic biomaterial, which consisted of two bcc solid solution phases in the as-cast and annealed states [26]. This HEA exhibited an equiaxed fine dendrite structure in the as-cast state and presented exceptional strength and deformability and superior biocompatibility, comparable to $\mathrm{CP}$ (commercially pure) Ti, indicating the possibility of using the

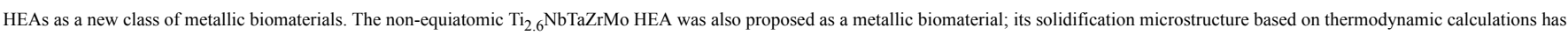
been reported [27].

\section{Biomedical and health care fields}

The effects of light elements like oxygen and nitrogen on biomedical $\alpha+\beta$ type and $\beta$ type alloys have been actively studied to advance functional improvement and cost reduction. TNTZ (Ti-29Nb-13Ta-4.6Zr) has been developed as a $\beta$ type biomedical Ti alloy. The effect of oxygen content on the mechanical and fatigue properties of TNTZ has been reported [28]. Figure 16 shows the maximum cycle stress-number of cycles to failure curves (S-N-curves) of the TNTZ-(0, 0,3, 0.5, 0.7 mass\%)O alloys [28]. The TNTZ-0.7O alloy exhibits the highest fatigue limit of $635 \mathrm{MPa}$, which is comparable to the commonly used Ti-6AL-4V ELI. The aging behavior and shape memory effect of the low $\operatorname{cost} \beta$ type Ti-Mn based alloys have been scrutinized [29]. Further, Mo addition to the Ti-Mn system caused the formation of deformation twins, which improved the strength ductility balance and fatigue characteristics [30]. 
Studies on surface modification based on morphology control and composition/phase control for biofunctionalization have been actively pursued. Preparation of $\mathrm{TiO}_{2}$ layers on $\mathrm{Ti}$ and its alloys using processes like thermal oxidation [31], anodic oxidation [32], and $\mathrm{NaOH}$ treatment and heating [33] has been reported. Dual functionalization of both antibacterial activity and bone compatibility was oriented by using the $\mathrm{TiO}_{2}$ layer as a visible-light active photocatalyst and carrier of metallic particles such as $\mathrm{Cu}, \mathrm{Zn}$, and $\mathrm{Ag}$. This has enabled us achieve "the self-maintenance function" required to prevent and treat infections such as peri-implantitis in the dental field.

\section{Shape memory alloys}

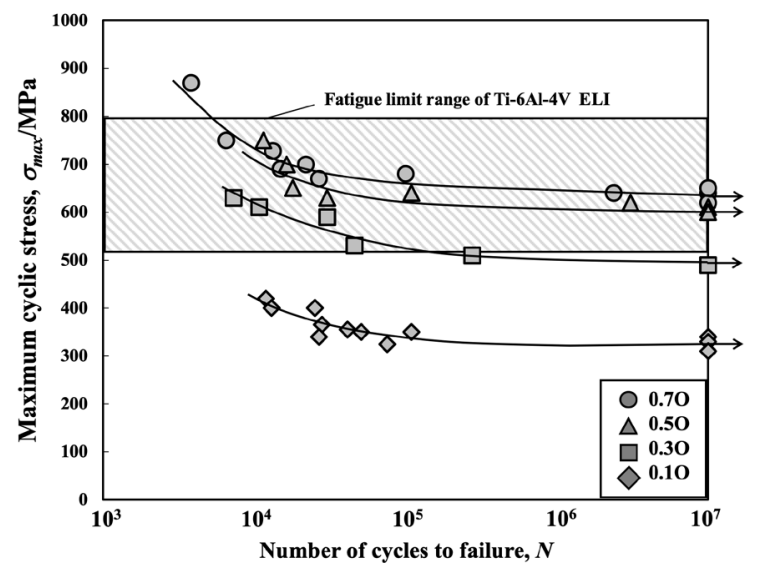

Recently, a new Ti-Zr-Nb-Sn alloy system was developed as an Ni-free biomedical superelastic alloy with exceptional recovery strain and superior biocompatibility [34]. A superior superelastic recovery strain of $6.0 \%$ was reported for Ti-18Zr-12.5Nb-2Sn, Ti-18Zr-11Nb-3Sn, and Ti-18Zr-9.5Nb-4Sn alloy subjected to cold-rolling and solution treatment due to the combined effects of superior transformation strain and strong recrystallization texture. The Ti-18Zr$11 \mathrm{Nb}-3 \mathrm{Sn}$ alloy exhibited excellent cyclic stability with an extremely narrow stress hysteresis of nearly $20 \mathrm{MPa}$. Moreover, the alloy was cytocompatible. Basic research on the plastic deformation in a single crystal of $\alpha^{\prime \prime}$ (orthorhombic) martensite of Ti-27 at\%Nb shape memory alloy has been reported (Fig. 17) [35] Four operative plastic deformation modes were observed, including two dislocation slips and two twinnings. The identified slips and twinning systems in the martensite phase have corresponding slips and twinning systems in the parent $\beta$ phase with which they share many similarities. The plastic deformation of the $\alpha^{\prime \prime}$ martensite was inherited from the parent $\beta$ phase.

Figure $16 \mathrm{~S}-\mathrm{N}$ curves of TNTZ-(0.1, 0.3, 0.5, 0.7 mass\%)O alloys with fatigue limit range of Ti-6AI-4V ELI [28]
$<$ Slip >

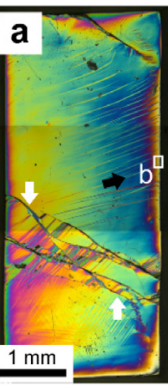

$<$ Twin >

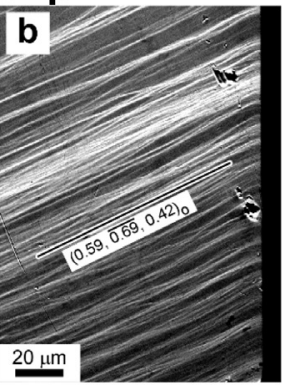

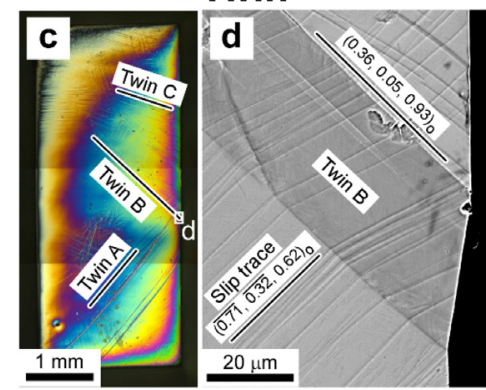

dislocation slip and deformation twinning [35].

\section{Additive manufacturing (AM)}

Studies on the formation of complex geometries and a crystallographic texture on Ti and its alloys using Powder Bed Fusion such as EBM (Electron Beam Melting) and SLM (Selective Laser Melting) have been actively conducted [36]. Figure 18 shows the Ti-6Al-4V acetabular cup fabricated using EBM. The cup has a well-controlled interconnected porous structure and spikes, which allow the growth of new bone deep in the cup and increase the interfacial strength between the cup and bone. An example of controlling crystallographic texture using scan strategies in SLM is shown in Fig. 19 [37]. Preferential orientation of $\langle 100>$ in biomedical $\beta$ type Ti-15Mo-5Zr-3Al alloy with a low Young's modulus can be achieved, which can allow the development of implants that can suppress stress shielding.

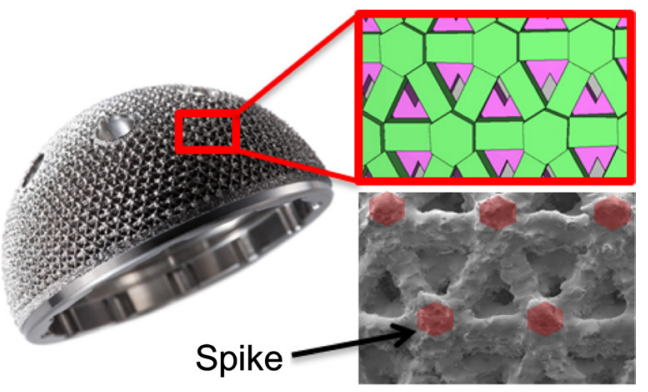

Figure 18 Ti-6Al-6V acetabular cup fabricated using EBM with optimized porous body shape
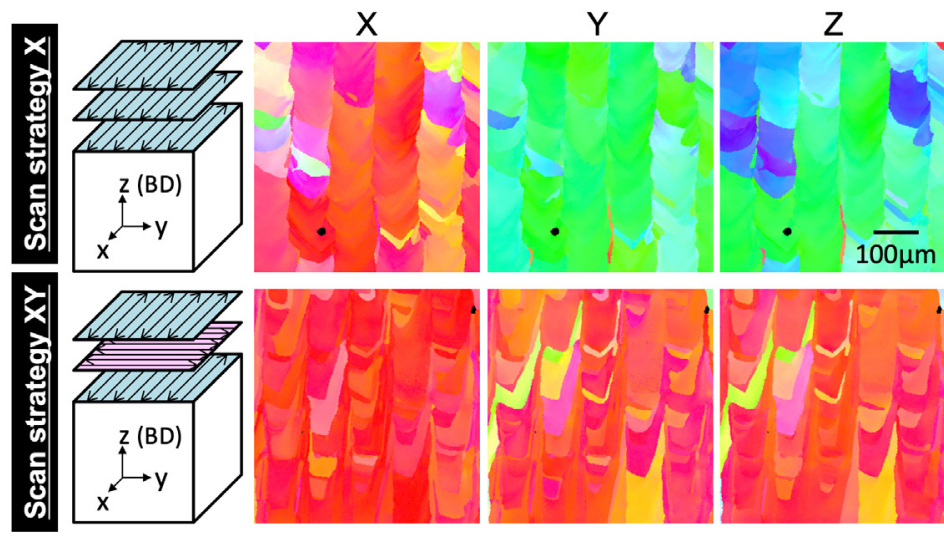

Figure 19 Crystal orientation of biomedical $\beta$ type Ti-15Mo-5Zr-3Al using scan strategy in SLM [37]. 
(Courtesy of Prof. Nakano, Osaka University)

The heat affected zone below the molten pool in the AM of metals forms unique microstructures through cyclic heat treatments. Figure 20 shows the microstructure of a vertical cross-section of Ti-48Al-2Cr-2Nb (at\%) alloy fabricated by EBM [38]. The microstructure is composed of two layers with different features. One is predominantly composed of lamellar-structured $\gamma / \alpha_{2}$ fine grains and fine equiaxed $\gamma$ grains, and the other is composed of coarser equiaxed $\gamma$ phase grains, which form a chain perpendicular to the building direction. High yield strength and elongation [38] and excellent fatigue properties [39] were achieved when the angle between EBM-building directions and stress loading direction was $45^{\circ}$.

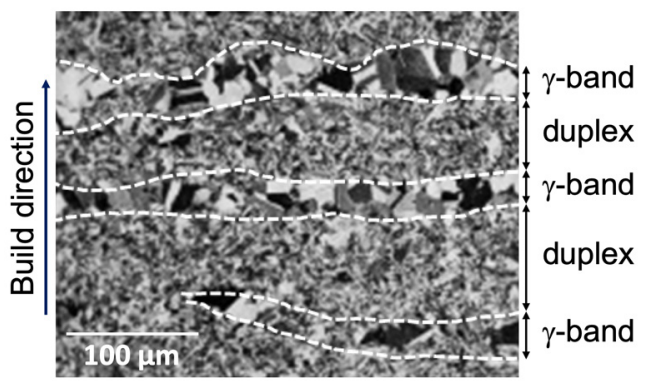

Figure 20 Microstructure of the vertical cross-section of Ti-48Al-2Cr-2Nb (at\%) alloy fabricated using EBM [38].

\section{Computational simulation}

Computational simulations on the phase stability, properties, and processing of Ti and its alloys based on first-principles calculations were conducted. Effects of third alloying elements on the transformation strains and phase stabilities of Ti-Nb based shape memory alloys at $0 \mathrm{~K}$ were investigated using the first-principles calculations [40]. In binary Ti-Nb alloys, the transformation strains and $\beta$ phase stabilities decreased with increasing $\mathrm{Nb}$ concentration. The effects of 45 different alloying elements $(\mathrm{X})$ on the transformation strains and phase stabilities of Ti-12.5 $\mathrm{Nb}$ (at $\%$ ) shape memory alloys at 0 $\mathrm{K}$ were studied. Further, the $\mathrm{X}$ contents of Ti-12.5Nb-X (at \%) ternary alloys were calculated under the condition that the martensitic transformation start temperature was equal to $300 \mathrm{~K}$. Promising candidates for alloying elements and concentrations required to obtain large transformation strains at room temperature were predicted. The predicted results indicated that the Ti-12.5Nb-17.8Hf (at $\%$ ) shape memory alloy exhibited the largest transformation strain value (Fig. 21) [40]).

Simulation of high temperature oxidation process of Ti and its alloys using first-principles molecular dynamics (MD) has been attempted [41][42]. The $\alpha$-Ti (0001) surface was modelled using an asymmetric $(4 \times 4)$ slab with 11 layers. Oxygen molecules were introduced to the Ti surface and reactions such as oxide formation on the Ti surface and oxygen dissolution to Ti $(\alpha$-case) were simulated from $300-973 \mathrm{~K}$. Figure 22 shows the MD snapshots of $\alpha$-Ti surface (0001) at oxidation periods of 0 to $50 \mathrm{ps}$ at $973 \mathrm{~K}$ [42]. Four oxygen molecules were introduced on to the surface every 10 ps. TiO-like oxide and $\alpha$-case formation were successfully simulated after an oxidation period of $50 \mathrm{ps}$. To elucidate the effect of $\mathrm{Si}$ on the oxidation behavior of Ti, four Ti atoms on the surface were substituted by Si atoms. The formation of $\alpha$-case was suppressed by the addition of Si [42], which agreed well with experimental results [43].

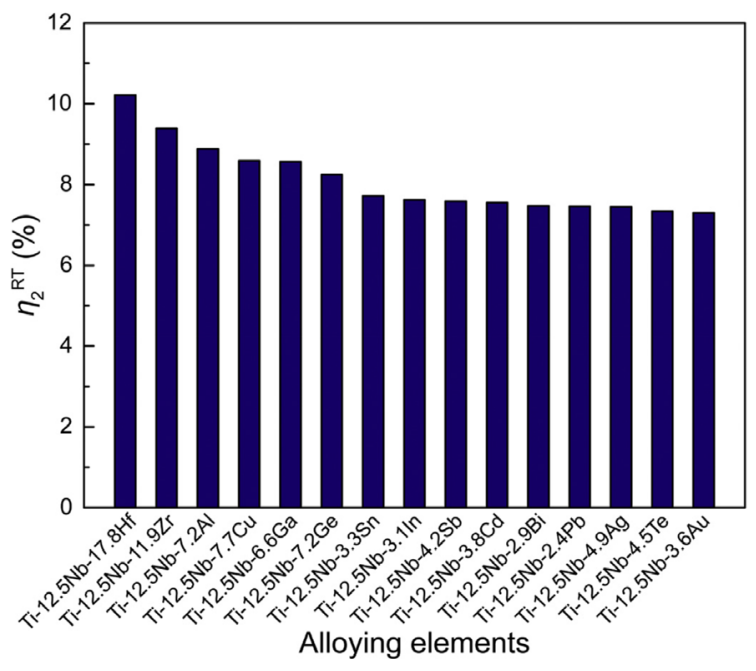

Figure 21 Transformation strain in Ti-12.5at $\% \mathrm{Nb}-\mathrm{X}$ alloy system under the condition of martensitic transformation temperature of $300 \mathrm{~K}[40]$.

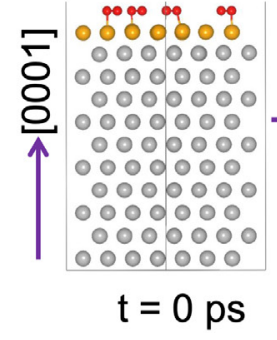

कorifige

000000

0000000

$\rightarrow 0000000$ 0000000 0000000 $\circ 000000$ $\circ 000000$ 0000000

$t=10 p s$

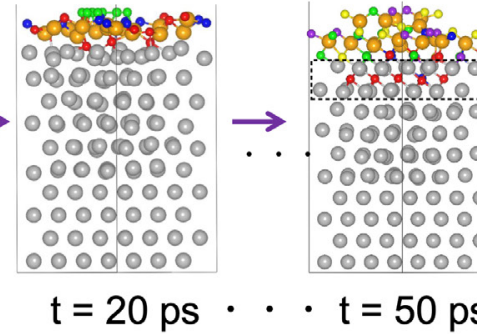

Figure 22 MD snapshots of $\alpha$-Ti surface (0001) at oxidation time of 0 to 50 ps at $973 \mathrm{~K}$ [42].

\section{Industrial fields}


The demand for Ti powder for AM, medical, and aerospace fields is expected to rise in the future. However, control of oxygen content is an important factor in the use of Ti powder in AM. Although most of the unused powder is reused during AM, usage limitations exist due to oxygen pickup. The number of reuses is important for cost reduction; an increase in the number of reuses will reduce cost. Thus, oxygen content in Ti powder has to be reduced. Oxygen content increases as the Ti powder becomes finer (Fig. 23). The Y-intercept of the figure corresponds to the oxygen content of the raw materials ( $\mathrm{Ti}$ ingots). Oxygen content in raw materials such as Ti sponge and ingots is important. A process to produce fine and spherical Ti-6Al-4V alloy powders for AM has been developed using technologies of highly pure Ti production (99.999\%) and Ti sponge and ingot making processes [44]. This powder exhibits both high flowability and high packing density and its oxygen content is as low as 0.05 mass\%.

Ti thin foil manufacturing by direct electro-deposition was developed during the NEDO (New Energy and Industrial Technology Development Organization) Structural Materials Project. Ti foils formed on the Mo sheet cathode through electrolysis, refining, and deposition in an electrolyte containing $\mathrm{TiCl}_{2}$ using raw materials such as low grade Ti and Ti sponge as anodes (Fig. 24). High purity Ti foils (oxygen content $<0.02 \mathrm{mass} \%$ ) of post-card size $\left(90 \times 150 \times 0.1 \mathrm{~mm}^{\mathrm{t}}\right)$ and good surface quality were successfully obtained. They can be easily separated from the cathode.

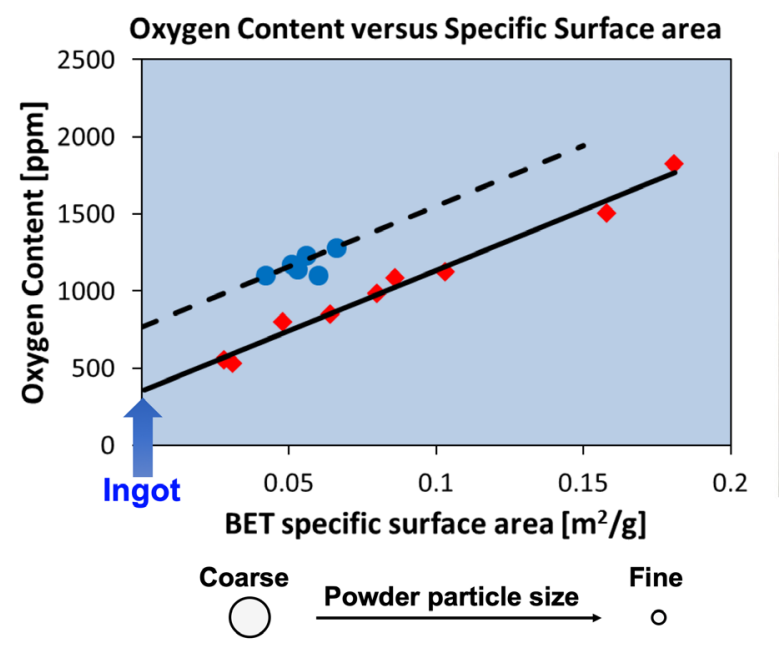

Figure 23 Relationship between relative surface area and oxygen content in Ti powder

(Courtesy of Osaka Titanium technologies Co., Ltd.).

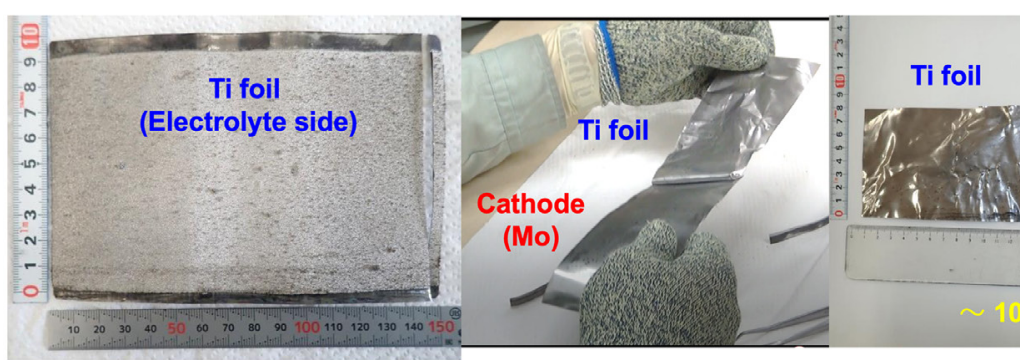

Figure 24 Ti thin foil manufacturing by direct electro-deposition (Courtesy of Toho Titanium Co., 1

In 2017, the five-storied pagoda of Sensoji Temple, Tokyo, was remodeled using 57,000 Ti roof tiles (Fig. 25). The weight of the Ti roof tile is much lower than that of conventional clay roof tile, which will improve the earthquake resistance of the building. In fact, Ti roof tile loss was not reported duringthe Great East Japan Earthquake in March 2011. In addition to roof tiles, the use of Ti sheet has been used at the Jiangsu Grand Theatre, China, in 2017 and M6B2 Tower of Biodiversity, Paris, in 2016.

Ti and its alloys have been used in motorcycles and automobiles to reduce the weight of their component parts. Recently, Ti exhaust systems such as muffler, engine valves, and connecting rods have been widely applied in sporty and large motorcycles [45]. The most recent example is the use of CP Ti JIS class-1 (TP270C) in the fuel tanks of mass-produced motorcycles due to its high corrosion resistance and good press formability. Fuel tanks made of CP Ti are shown in Fig. 26 [46]. Further, to conform to permeation restriction regulations imposed by EURO 5 and other regulations, fuel tanks made of polyethylene must be multi-layered and thick to prevent gasoline permeation. A fuel tank made of $\mathrm{CP}$ Ti weighs $40 \%$ lesser than a polyethylene tank; therefore, the former has considerably thinner walls than the latter.

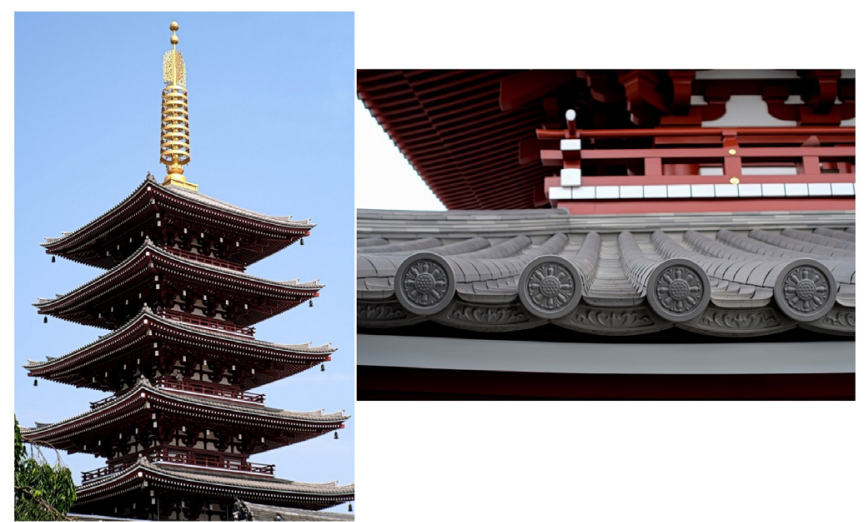

Figure 25 Ti roof tiles used in the five-storied pagoda of Sensoji Temple, Tokyo (Courtesy of Nippon Steel Co., Ltd.).

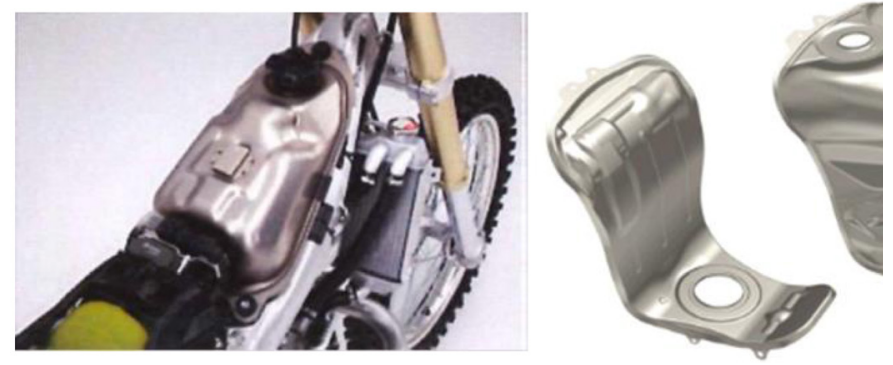

Figure 26 Appearance and CAD component drawing of a fuel tank made of TP270C on motocrosser frame (Cot Ltd. and Nippon Steel Co., Ltd.).

\section{Conclusion}


Since 2013, the JTS has held annual meetings on Ti for young scientists and engineers. The meetings are aimed to boost human resource development in Ti related fields in Japan, and propose multiple events such as presentations from researchers under 40 and factory tours. Several research groups focusing on Ti have been organized and are actively collaborating with the Japan Institute of Metals and Materials, the Iron and Steel Institute of Japan, and the Japan Institute of Light Metals. As highlighted by the national projects such as SIP and NEDO Structural Materials Project, attention focused on Ti is quite high in Japan. Industry-academia-government collaboration is expected to promote Ti research and development and human resource development centering on the JTS.

\section{$\underline{\text { Acknowledgments }}$}

The authors would like to thank the Japan Titanium Society, Nippon Steel Co., Ltd., Toho Titanium Co., Ltd., Osaka Titanium technologies Co., Ltd., Daido Steel Co., Ltd., and Kobe Steel Ltd. for offering materials needed to prepare this manuscript. We would also like to thank Prof. M. Niinomi of Tohoku University, Prof. M. Ikeda of Kansai University, Prof. R.O. Suzuki of Hokkaido University, Prof. T.H. Okabe of The University of Tokyo, Prof. H. Hosoda and Dr. M. Tahara of Tokyo Institute of Technology, Dr. Y. Yamabe-Mitarai and Dr. R. Sahara of NIMS, Prof. T. Nakano of Osaka University, and Prof. T. Uesugi of Osaka Prefecture University for providing information on their publications and data published.

\section{References}

[1] Japan Titanium Society, statistical data, (2019).

[2] http://www.jst.go.jp/sip/k03/sm4i/en/index.html

[3] http://www.jst.go.jp/sip/k03/sm4i/en/project/project-b.htm

[4] K. Yamanaka, H. Matsumoto, A. Chiba, Adv. Eng. Mater. 21 (2019) 1800775.

[5] H. Matsumoto, D. Naito, K. Miyoshi, K. Yamanaka, A, Chiba, Y. Yamabe-Mitarai, Sci. Tech. Ad. Mater. 18 (2017) 893-904.

[6] Y. Nagata, G. Miyamoto, T. Furuhara, Proc. of the PRICM 9 (2016) 654-657.

[7] Y. Yamabe-Mitarai, S. Kuroda, N. Motohashi, H. Matsumoto, G. Miyamoto, E. Chandiran, Y. Yoshida, Y. Itsumi, Mater. Trans. 60 (2019), in press.

[8] M. Niinomi, T. Akahori, M. Nakai, Y. Koizumi, A. Chiba, T. Nakano, T. Kakeshita, Y. Yamabe-Mitarai, S. Kuroda, N. Motohashi, Y. Itsumi, T. Choda, Mater. Trans. 60 (2019), in press.

[9] Y. Kanda, Y. Yoshida, Proc. of Inter. Conf. on Tribology in Manufacturing Process, (2016) 200-207.

[10] M. Niinomi, T. Akahori, M. Nakai, Y. Koizumi, A. Chiba, T. Nakano, T. Kakeshita, Y. Yamabe-Mitarai, S. Kuroda, N. Motohashi, Y. Itsumi, T. Choda, Proc. of Ti-2019, Nantes, France.

[11] Y. Yamabe-Mitarai, S. Kuroda, N. Motohashi, H, Matsumoto, G. Miyamoto, Y. Yoshida, K. Yamanaka, M. Niinomi, Y. Itsumi, Proc. of Ti-2019, Nantes, France.

[12] N. Suzuki, M. Tanaka, H. Noguchi, S. Natsui, T. Kikuchi, R.O. Suzuki, Mater. Trans. 58 (2017) 367-370.

[13] R.O. Suzuki, Y. Yashima, N. Suzuki, S. Natsui, T. Kikuchi, Proc. of Ti-2019, Nantes, France.

[14] M. Ohta, S. Satoh, T. Kuzuya, S. Hirai, M. Kunii, A. Yamamoto, Acta Mater. 60 (2012) 7232-7240.

[15] O. Takeda, T.H. Okabe, JOM (2018). https://doi.org/10.1007/s11837-018-3278-1

[16] M. Watanabe, F. Sato, K. Ueda, D. Matsuwaka, F. Kudo, T. Narushima, Metall. Mater. Trans. B, accepted

[17] V. Dembovský, Plasma Metallurgy: The Principles, Materials Science Monographs 23, Elsevier, Amsterdam, (1985).

[18] D. Matsuwaka, F. Kudo, H. Ishida, T. Deura, Proc. of Ti-2019, Nantes, France.

[19] T. H. Okabe, C. Zheng, Y. Taninouchi, Metall. Mater. Trans. B 49 (2018) 1056-1066.

[20] C. Zheng, T. Ouchi, A. Iizuka, Y. Taninouchi, T.H. Okabe, Metall. Mater. Trans. B 50 (2019) 622-631.

[21] T. Konno, K. Tamura, Y. Itsumi, K. Yokochi, K. Akazawa, H. Oyama, T. Choda, Proc. of Ti-2019, Nantes, France.

[22] S. Matsunaga, A. Serizawa, Y. Yamabe-Mitarai, Mater. Trans. 57 (2016) 1902-1907. 
[23] K. Shimagami, S. Matsunaga, A. Yumoto, T. Ito, Y. Yamabe-Mitarai, Mater. Trans. 58 (2017) 1404-1410.

[24] K. Shimagami, T. Ito, Y. Toda, A. Yumoto, Y. Yamabe-Mitarai, Mater. Sci. Eng. A 756 (2019) 46-53.

[25] D.B. Miracle, O.N. Senkov, Acta Mater. 122 (2017) 448-511.

[26] M. Todai, T. Nagase, T. Hori, A. Matsugaki, A. Sekita, T. Nakano, Scripta Mater. 129 (2017) 65-68.

[27] T. Nagase, M. Todai, T. Hori, T. Nakano, J. Alloys Compd. 753 (2018) 412-421.

[28] H. Liu, M. Niinomi, M. Nakai, S. Obara, H. Fujii, Mater. Sci. Eng. A 704 (2017) 10-17.

[29] M. Ikeda, M. Ueda, Mater. Sci. Forum 879 (2016) 119-124.

[30] P.F. Santos, M. Niinomi, H. Liu, K. Cho, M. Nakai, A. Trenggono, S. Champagne, H. Hermawan, T. Narushima, Mater. Design. 110 (2016) $414-424$.

[31]T. Ueda, K. Ueda, K. Ito, K. Ogasawara, H. Kanetaka, T. Mokudai, Y. Niwano, T. Narushima, J. Biomed. Mater. Res. A. 107 (2019) $991-1000$.

[32] M. Shimabukuro, Y. Tsutsumi, R. Yamada, M. Ashida, P. Chen, H. Doi, K. Nozaki, A. Nagai, T. Hanawa, ACS Biomater. Sci. Eng. (2019) DOI: 10.1021/acsbiomaterials.8b01058

[33] M. Kawashita, Y. Iwabuchi, K. Suzuki, M. Furuya, K. Yokota, H. Kanetaka, Colloids Surf. A 555 (2018) 558-564.

[34] J. Fu, A. Yamamoto, H.Y. Kim, H. Hosoda, S. Miyazaki, Acta Biomater. 17 (2015) 56-67.

[35] M. Tahara, N. Okano, T. Inamura, H. Hosoda, Sci. Rep. 7 (2017) 15715.

[36] T. Nakano, T. Ishimoto, Materia Japan 58 (2019) 181-187.

[37] T. Ishimoto, K. Hagihara, K. Hisamoto, S-H. Sun, T. Nakano, Scripta Mater. 132 (2017) 34-38.

[38] M. Todai, T. Nakano, T. Liu, H.Y. Yasuda, K. Hagihara, K. Cho, M. Ueda, M. Takeyama, Additive Manufacturing 13 (2017) 61-70

[39] K. Cho, R. Kobayashi, J.Y. Oh, H.Y. Yasuda, M. Todai, T. Nakano, A. Ikeda, M. Ueda, M. Takeyama, Intermetallics 95 (2018) 1-10.

[40] D. Minami, T. Uesugi, Y. Takigawa, K. Higashi, J. Alloys Compd. 716 (2017) 37-45.

[41] S.K. Bhattacharya, R. Sahara, K. Ueda, T. Narushima, Sci. Tech. Ad. Mater. 18 (2017) 998-1004.

[42] S.K. Bhattacharya, R. Sahara, S. Suzuki, K. Ueda, T. Narushima, Appl. Surf. Sci. 463 (2019) 686-692.

[43] K. Maeda, S. Suzuki, K. Ueda, T. Kitashima, S.K. Bhattacharya, R. Sahara, T. Narushima, J. Alloys Compd. 776 (2019) 519-528.

[44] T. Onishi, Y. Ohashi, Titanium Japan 65 [4] (2017) 3-6

[45] K. Takahashi, Proc. of Ti-2019, Nantes, France.

[46] K. Hirano, Y. Chihara, SAE International, 2017, SAE 2017-32-0049. 